\title{
The Comparative Analysis of Culture Specific Items in Translation of the Novel "Spartacus" from English into Persian
}

\author{
Elham Sasaninejad (Corresponding author) \\ Islamic Azad University South Tehran Branch, Iran \\ Maryam Delpazir \\ Faculty of Foreign Languages, Kharazmi University, Iran
}

Received: 20-11-2014

doi:10.7575/aiac.ijclts.v.3n.1p.39
Accepted: 28-12- 2014

Published: 01-01- 2015

\begin{abstract}
Translation has always been considered a communication tool among different cultures and languages. Hence, the investigation of translations across history can reflect the dominant translational approaches and strategies in a specific era. The present study is descriptive-analytical corpus based aiming at investigation of utilized strategies in translation of culture specific items from English into Persian. Here, the researchers have focused on the novel Spartacus written by Howard Fast and its Persian translation by Ebrahim Yunesi as the corpus of the study. After analyzing the corpus according to the model presented by Pedersen (2005), it was revealed that the translator has adopted a target-oriented approach. Moreover, substitution strategy was seen to be used the most by the translator.
\end{abstract}

Keywords: culture specific items, source- oriented, Strategy, target-oriented, Translation

\section{Introduction}

\subsection{Theoretical background of the study}

Across the history, there has been a vast and deep relation between culture and literature and literature has had a great responsibility in transferring divergent cultures. Furthermore, translation has been considered as a fundamental tool for communication of thoughts and cultures.

Many theorists have been engaged in defining culture, its relation to the translated texts and treating the culture-specific items.

According to the American theorist Lawrence Venuti, translation is "a process by which the chain of signifiers that constitutes the source-language text is replaced by a chain of signifiers in the target language which the translator provides on the strength of an interpretation" (Venuti 1995: 17). Its aim is: "to bring back a cultural other as the same, the recognizable, even the familiar; and this aim always risks a wholesale domestication of the foreign text, often in highly self-conscious projects, where translation serves an appropriation of foreign cultures for

According to Nida and Taber, cultural translation is "a translation in which the content of the message is changed to conform to the receptor culture in some way, and/or in which information is introduced which is not linguistically implicit in the original" (Nida and Taber 1969/1982: 199).

Larson proposes that "different cultures have different focuses. Some societies are more technical and others less technical." This difference is reflected in the amount of vocabulary which is available to talk about a particular topic (Larson 1984: 95).

Newmark also introduced the expression 'cultural word' which the readership is unlikely to understand and the translation strategies for this kind of concept depend on the particular text-type, requirements of the readership and client and importance of the cultural word in the text (Newmark 1988: 96).

Baker refers to the cultural words and states that the SL words may express a concept which is totally unknown in the target culture. She points out that the concept in question may be "abstract or concrete, it may relate to a religious belief, a social custom, or even a type of food." Baker then, calls such concepts 'culture specific items' (Baker 1992: 21).

Nord uses the term 'cultureme' to refer to these culture specific items. She defines cultureme as "a cultural phenomenon that is present in culture X but not present (in the same way) in culture Y" (Nord 1997: 34).

Gambier also refers to such concepts as 'culture-specific references' and asserts that they connote different aspects of life such as education, politics, history, art, institutions, legal systems, units of measurement, place names, foods and drinks, sports and national pastimes, as experienced in different countries and nations of the world. (Gambier 2004: 159)

Considering the great role of cultural items in translation and their potential number in literary texts, the present study seeks to answer the following questions: 
1. Has the translator adopted target-oriented or source-oriented approach in his translation process?

2. Which strategy has been used the most in translation of culture specific items?

\subsection{Theoretical framework}

For data analysis, the present study has made use of the model proposed by Pedersen (2005). He divides culture specific items into two main categories of intra-linguistic culture bound references and extra-linguistic culture bound references (ECR). The intra-linguistic culture bound references are made up of idioms, proverbs, slangs and certain dialects whereas the second division includes cultural items which are apart from the system of a certain language.

According to Pedersen (2005) extra-linguistic culture bound references are of two categories: source- language oriented and target- language oriented.

Source- language oriented strategies include Retention, specification, and direct translation; however generalization, substitution, and omission fall within the frame of target- language oriented strategies.

1.2.1 Source- language oriented culture bound items:

\subsubsection{Retention}

Retention is the most SL-oriented strategy, as it allows an element from the SL to enter the TT.

\subsubsection{Specification}

Specification means leaving the ECR in its untranslated form, but adding information that is not present in the ST, making the TT ECR more specific than the ST ECR. This is done in one of two ways: either through Explicitation or Addition.

\subsection{Explicitation}

Explicitation is here used in a very restricted sense. Explicitation could be seen as any strategy involving expansion of the text, or spelling out anything that is implicit in the ST. In the present model, however, Explicitation means that the added material is latent in the STECR, as part of the expression side (the name) of the ECR. Examples of this are the spelling out of an acronym or abbreviation (often combined with other strategies), the adding of someone's first name or the completion of an official name to disambiguate an ECR for the Target Culture (TC) audience, which may not be as familiar with the ECR as the original Source Culture (SC) audience is.

\subsection{Addition}

This means that the added material is latent in the ECR, as part of the sense or connotations of the ECR. By using this strategy, the translator intervenes to give guidance to the TC audience.

\subsubsection{Direct translation}

This strategy could hardly be used on proper names, but it is not uncommon for rendering the names of companies, official institutions, technical gadgetry etc.

Unlike the strategies of Specification and Generalization, the semantic load of the ST ECR is unchanged: nothing is added, or subtracted. There is no effort made to transfer connotations or guide the TT audience in any way. In the present model, the strategy is divided into two subcategories, based on the outcome of the strategy: Calque and Shifted. A Calque would be the result of stringent literal translation and it may appear exotic to the TT audience.

\subsubsection{Target- language oriented culture bound items}

\subsubsection{Generalization}

This strategy (which typically, albeit not necessarily, involves translation) means replacing an ECR referring to something specific by something more general. Typically, this involves hyponymy.

\subsubsection{Substitution}

This strategy involves removing the ST ECR and replacing it with something else, either a different ECR or some sort of paraphrase, which does not necessarily involve an ECR.

\subsection{Cultural transmission}

The strategy of Cultural Substitution means that the ST ECR is removed, and replaced by a different ECR.

\subsection{Paraphrase}

This strategy involves rephrasing the ECR, either through "reduction to sense" (Leppihalme1994: 125), or by completely removing all trace of the ECR and instead using a paraphrase that fits the context.

\subsubsection{Omission}

As Toury has pointed out (1995: 82), Omission is a valid translation strategy, and in the present model it simply means replacing the ST ECR with nothing.

It should be mentioned that the present study seeks for the Extra-linguistic culture bound items and has nothing to do with Intra-linguistic culture bound ones.

This study aims at investigation of the strategies used to translate culture specific items in translation of the novel Spartacus written by Howard Fast in order to answer these questions: what kind of strategies are adopted in the 
translation of culture specific items, which strategy have been used the most and finally determining whether the translation was source- language oriented or target- language oriented.

\section{Review of the Related Literature}

As it was mentioned before, language and literature are two powerful and effective tools playing significant roles in communicating different cultures and civilizations. Throughout history, various literary genres have been used as tools to dominate other cultures and also as powerful weapons in the battle ground of soft war.

Among all types of translation, literary translation has engaged persistent minds of theorists such as Landers, Bush, Lambert, and Newmark, all of them have been concerned with the process of literary translation, the translator, and the reader.

The above mentioned theorists have come up to several considerations about type of translation, namely literary translation, and especially treating its indispensably related culture.

According to Landers, literary translation "lets one consistently share in the creative process of translation" (Landers 2001: 4-5); "literary translation entails an unending skein of choices" (Landers 2001: 9).

Bush has stated that literary translation is "an original subjective activity at the center of a complex network of social and cultural practices" (Bush 1998: 127).

According to Lambert (1998), "a published translation is the fruit of a substantial creative effort by the translator, who is the key agent in the subjective activity and social practice of translation."

Newmark concedes that "it usually happens that the literary translator first has to deal with words set on the page by an author 'who may be dead physically or metaphorically and now lives in the variegated readings by a host of readers of the source language" " (Newmark 1998: 117).

Undoubtedly, as a bridge among languages and cultures, translation has played a significant role in this communication or even in wars and also it can define the domination and higher position of languages and cultures to each other.

Toury (1980) believes that literal translation is the product of a very complex process which involves two languages and cultures. According to him, translation can be reached from two perspectives:

1. Translation is a value in the target literature and possesses a separate nature different from that of the source text.

2. The product is a translation which is the representative of the source text in target culture.

In this regard, two dominant approaches in translation enact: source-oriented approach and target-oriented approach. The development of translation throughout history has shown that translation has been reconsidered from pure linguistic source-oriented transfer to a meaning-based target-oriented communication. This matter provoked the emergence of several theories in the field of translatology and translation studies.

From the point of view of source-oriented theories, the translator tries to transfer the source language culture specific items to the target language properly. In this way he facilitates the communication between source language and target language. In some cases this leads to literal or word or word translations which are vague and awkward for target readers and makes the comprehension difficult.

Today, the study of cultural effects and the translation of culture specific items have become one of the important subjects in translation studies. While explaining the changes within the translational approaches, Bassnet and Lefever (1998) state that for some time the most important question in translation studies was: "Is translation teachable?" or "how could one study translation?"; however the subject of translation studies has now been redefined. Today, the issue at stake is the text located in a network of cultural signs of source and target languages. This indicates the importance and the role of cultural elements in the field of translation.

Rodriguez (1996) defines cultural items as: "textual items having connotative meaning and function in the source text whose transfer to the target language seems difficult. This problem is due to absence of equivalent in the target language or a different equivalent in the target language system." Here the role of translator as a bridge between the two languages becomes prominent.

A few studies have been done investigating how culture specific items have been translated. For example, Hatim (1997) studies the culture bound items in the translation of audiovisual texts. Similarly, Leppihalme(1994) deals with the translation of illusions and how they cause "cultural bumps". Furthermore, Nedergaard-Larson (1993) has investigated the problems in translation of culture bound items in subtitling.

\section{Research design}

The present study is a descriptive analytical, corpus-based research based on the model presented by Pedersen (2005). It attempts to describe, analysis, and explain the object of study using corpus - driven data

\subsection{Corpus of the study}

The corpus of the present study consists of two components; The English component and its corresponding Persian component. For the English part of the corpus, the novel Spartacus which is written by Howard Fast has been selected and its Persian translation by the Iranian translator EbrahimYunesi constituted the other component of the corpus.

The Novel Spartacus is a historical novel written by Howard Fast in 1951. It is about the historic slave revolt led by Spartacus around 71 BCE. The book is admired in the literary genre and it inspired the 1960 film directed by Stanley Kubrick and the 2004 TV adaptation by Robert Dornhelm. It is mentionable that the novel "Spartacus" was one of the best-selling works of the author. Fast himself was one of the 20th century's best writers who has won several prizes including the Stalin International peace prize in 1953.

The Persian translation of Spartacus has been done by EbrahimYunesi, one of the most prominent and noticeable Iranian translators who has compiled and translated many literary books which had undergone numerous republications. 
One of his brilliant works which falls within the domain of literary translation is the Persian translation of Spartacus. The novel was a best-selling work and like the original has undergone several republications.

It should also be mentioned that the researchers became motivated to use this novel as their corpus of the study since both the original novel and its Persian translation were bestselling in their recipient cultures and the theme of the book was based on human values and commitments.

\subsection{Procedure}

At the first step, the researchers have read both the original novel and its Persian translation. The researchers have investigated the first one third of the books and extracted 506 cases of culture specific items. Finally, they have selected 110 randomly chosen words, phrases and sentences.

The researchers have compared them contrastively with their translations and recognized the strategies used by the translator and then evaluated the frequency of the occurrences of strategies which were at the heart of the research model presented by Pedersen (2005).

For the inter-rater reliability to be established, the researchers have done the investigations separately and then compared them and come to consensus about the items selected.

\section{Results}

After precisely studying the novel Spartacus written by Howard Fast and its Persian translation by EbrahimYunesi, 110 culture specific elements were randomly chosen from among the text. Then the strategies used in their translation into Persian were analyzed according to the model presented by Pedersen (2005).

From among the 110 elements which were selected randomly, it was found that 32 of them had been translated sourceorientedly and 68 had been translated target-orientedly. The following figures and diagrams manifest the frequency of source-oriented and target-oriented strategies in the corpus of the present study.

Table1. The total frequency of source-oriented strategies and target-oriented strategies

\begin{tabular}{lll}
\hline Strategy & Source-oriented & Target-oriented \\
\hline Number & 42 & 68 \\
Frequency & $38.18 \%$ & $61.82 \%$ \\
\hline
\end{tabular}

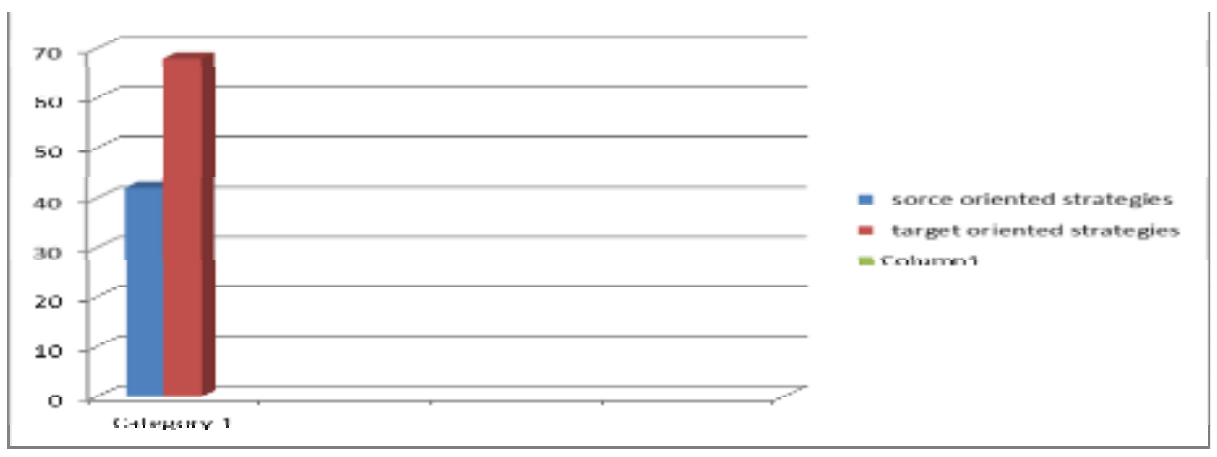

Figure 1.The total frequency of source-oriented strategies and target-oriented strategies

Among 42 items which had been recognized being translated source-orintedly, 10 retentions, 31 specifications, and 1 case of direct translation were observed. The following table and figure makes the results clear.

Table 2. The particular frequency of source-oriented strategies

\begin{tabular}{llll}
\hline Strategy & Retention & Specification & Direct translation \\
\hline Number & 10 & 31 & 1 \\
Frequency & $23.81 \%$ & $73.81 \%$ & $2.38 \%$ \\
\hline
\end{tabular}

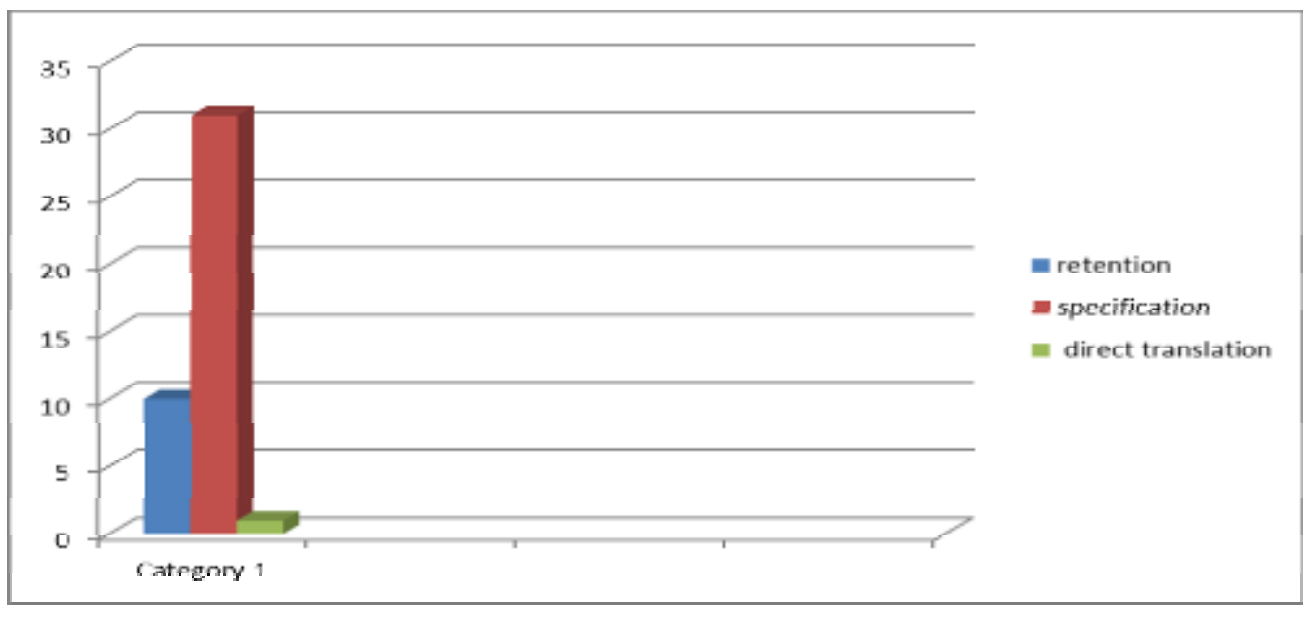

Figure 2.The frequency of source-oriented strategies 
Among 68 items which had been translated according to target-oriented strategies, 47 of them were substitution, 21 omission and there were no cases of generalization. Table and figure 3 present the frequency of strategies used in the translation of intended corpus.

Table 3.The frequency o target-oriented strategies

\begin{tabular}{llll}
\hline Strategy & Generalization & Substitution & Omission \\
\hline Number & 0 & 47 & 21 \\
Frequency & 0 & $69.12 \%$ & $30.88 \%$ \\
\hline
\end{tabular}

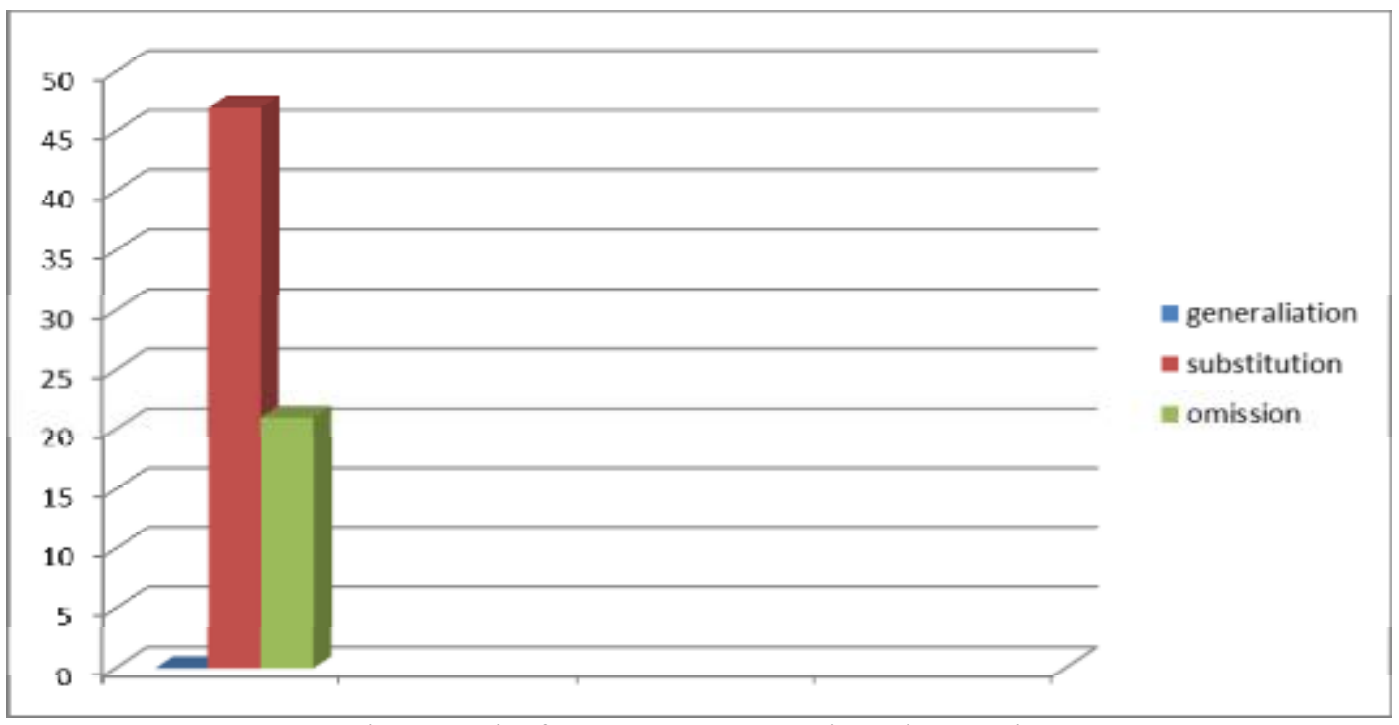

Figure 3.The frequency o target-oriented strategies

Table 4 presents the frequency of all of the strategies applied in the corpus.

Table 4.the frequency of all of the strategies used in the Persian translation of the novel Spartacus

\begin{tabular}{lllllll}
\hline Strategy & Retention & Specification & $\begin{array}{l}\text { Direct } \\
\text { translation }\end{array}$ & Generalization & Substitution & Omission \\
\hline Number & 10 & 31 & 1 & 0 & 47 & 21 \\
Frequency & $9.09 \%$ & $28.18 \%$ & $0.91 \%$ & 0 & $42.73 \%$ & $19.09 \%$ \\
\hline
\end{tabular}

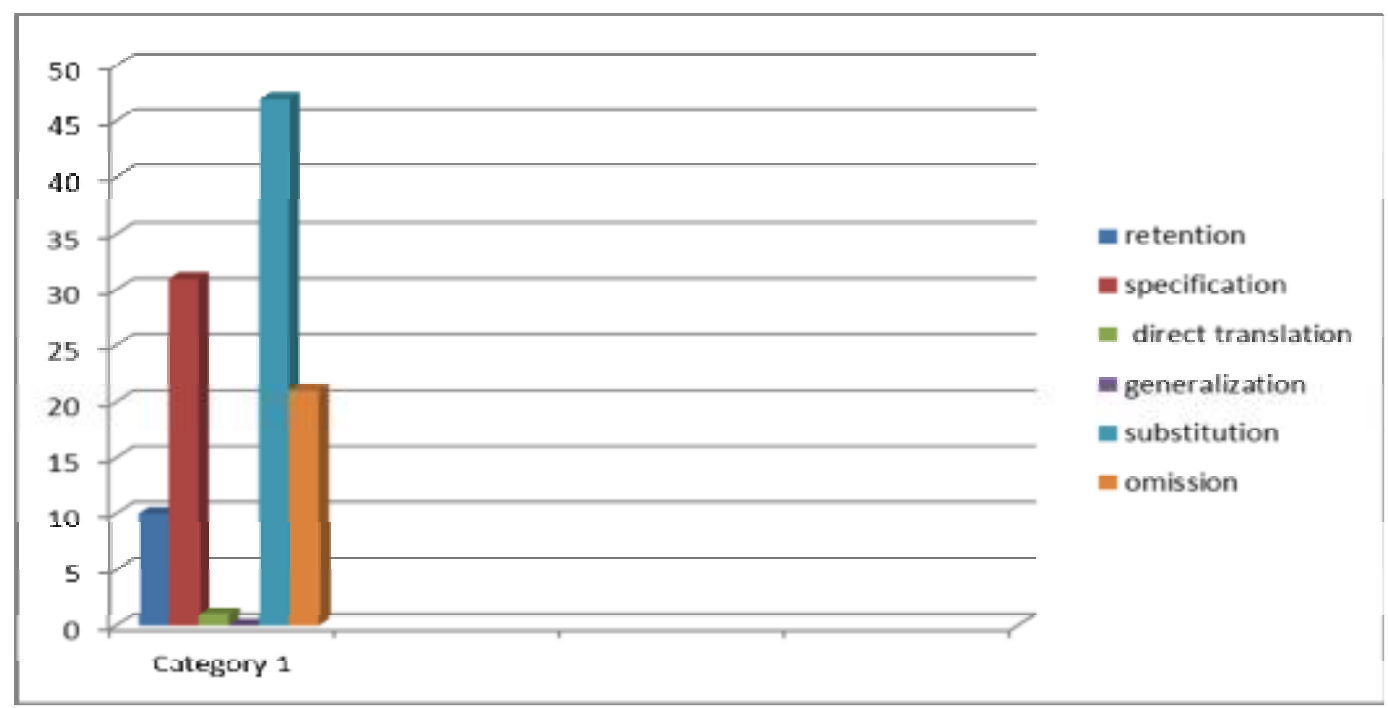

Figure 4. The frequency of all of the strategies used in the Persian translation of the novel Spartacus

\section{Conclusion}

As mentioned previously, the present research aimed at analyzing the strategies used in the translation of culture specific items in the translation of the novel Spartacus written by Howared Fast and its Persian translation by Ebrahim Yunesi. The research intended to answer the following questions: which strategies the translator has used in translating the culture specific items; and more specifically which strategy has been used the most. At the end, the researchers have investigated the corpus to find out whether the translation was source-oriented or target-oriented.

After studying the original book and its translation and investigating culture specific items in the first one third of them, the researchers found 506 culture specific items from which 110 cases were selected randomly.

According to Pedersen (2005) extra-linguistic culture bound references are of two categories: source- language oriented and target- language oriented. Source- language oriented strategies include Retention, specification, and direct 
translation; however generalization, substitution, and omission fall within the frame of target- language oriented strategies.

Based on the investigations and the derived results presented before, from among the 110 randomly chosen items, 42 items (about 38.18 percent) had been translated source-orientedly and 68 items (about 61.81 percent) had been translated target-orientedly.

Regarding the research question number 1 which was introduced previously, the results indicate that the translator had adopted a target-oriented approach in his translation of the culture specific items of the novel Spartacus written by Howard Fast.

Regarding the research question number 2, comparing the strategies separately and according to the previous statistics, it was found that the substitution strategy occurred in 47 out of 110 cases and contains about 42.72 percent of the corpus.

The researchers assumed that the target-orientedness of the translation has improved its readability and acceptance among Persian readers and it is possibly the reason for it to be a best-selling work and having several republications. However, in order to prove this assumption scientifically, further researches are required to be established.

\section{References}

Alvarez Rodriguez, R. (1996). Translation, Power, Subversion Topics in Translation, p. 58.

Baker, M. (1992) In Other Words: A Coursebook on Translation. London and New York: Routledege.

Bassnett, S; Lefevere, A. (1998). Constructing Cultures : Essays On Literary Translation Topics in Translation; p.123

Bush, P. (1998) "Literary Translation." In: M. Baker, ed. Routledge Encyclopedia of Translation Studies, London: Routledge, 127-130.

Fast, H. (1951) Spartacus, New York: Bantam books \& Crown Publishers, Inc.

Gambier, Y. (2007) Doubts and Directions in Translation Studies, The Netherlands: John Benjamins.

Hatim, B. (1997): Communication Across Cultures: Translation Theory and ContrastiveText Linguistics. Exeter: University of Exeter Press.

Lambert, J. (1998)"Literary Translation."In: M. Baker, ed. Routledge Encyclopedia of Translation Studies. London: Routledge, 130-134.

Landers, C. E. (2001) Literary Translation: A practical Guide, New Jersey University Press: Multilingual Maters.

Larson, M. L. (1984) Meaning-Based Translation: A Guide to Cross-Language Equivalence. Lanham and New York: UniversityPress of America, Inc.

Leppihalme, R. (1994): Culture Bumps: On the Translation of Allusions. Helsinki:University of Helsinki, English Department Studies 2.

Nedergaard-Larsen, B. (1993): 'Culture-Bound Problems in Subtitling'. In Perspectives: Studies in Translatology.1993; 2: 207-242.

Newmark, P. (1988) A Textbook of Translation.New York and London Prentice- Hall.

Newmark, P. (1998) More Paragraphs on Translation. New Jersey University Press: Multilingual Maters.

Nida, E.A. and C. R. Taber (1969) The Theory and Practice of Translation. Leiden: E.J. Brill.

Nida, E. (1964). Toward a Science of Translating: With Special Reference to Principles and Procedures Involved in Bible Translating. Netherland: Brill Academic Publishers

Nord, C. (1997): Translating as a Purposeful Activity: Functionalist ApproachesExplained. Manchester: St. Jerome Publishing.

Pedersen, J (2005). How Culture Is Rendered in Subtitles?,MuTra 2005 - Challenges of Multidimensional Translation: Conference Proceedings.

Toury, G. (1995): Descriptive Translation Studies - And Beyond. Amsterdam \&Philadelphia: John Benjamins.

Venuti, L. (1995): The Translator's Invisibility: A History of Translation. London -New York: Routledge

----- (2000): The Translation Studies Reader. London \& New York: Routledge.

Yunesi, E. (1983): Spartacus: Tehran: Amirkabir publications. 